\title{
LINGUISTIC LANDSCAPE SIGNS IN E-TEXTBOOKS: TEACHING LANGUAGE AS A COMPASS FOR EXPLORING MULTIMODAL TEXTS, MULTILINGUALISM, AND DIGITAL RESOURCES
}

\author{
Solvita Burr \\ University of Latvia, Latvia
}

\begin{abstract}
Rapid technological development and the growth of educators' and students' digital skills have allowed e-textbooks to take root in different school subjects' pedagogical practices. This article's aim is to compare two e-textbooks - A Guide for Exploring City Texts (Berra (Burr), 2020) and Linguistic Landscapes in English Language Teaching: A Pedagogical Guidebook (Solmaz \& Przymus, 2021) - in terms of their technological and pedagogical frameworks and to discuss the benefits and disadvantages of using a language e-textbook which heavily utilizes linguistic landscape signs.

The comparison shows that the e-textbooks' main technological advantages are hyperlinking, bookmarking, highlighting, annotating, and searching. Their content uncovers pedagogical concepts they both share: (1) authenticity, (2) resourcefulness, (3) connectivism, (4) a focus on text genres. Language in both textbooks is understood in the context of semiotic resources, so knowledge and skills in one language are inextricably linked to awareness of other languages, semiotic consciousness, and multiliteracies. The learning process in both e-textbooks is designed in a way that students interactively create and contribute knowledge and apply them in various real-life situations.

There are a few drawbacks of the e-textbooks. First, their current technological do not allow for changing the order, length, or content of chapters, subchapters, or sections. Second, a lack of space for writing answers in e-textbooks, which can be frustrating for students. Third, none of the e-textbooks provides content for the entire study year/course, language level, or national subject standard.
\end{abstract}

Keywords: e-textbooks, first language, linguistic landscape, multilingualism, multiliteracies, online educational resources, second language. 


\section{Introduction}

Rapid technological development, changes in human socialization habits, and the growth of educators' and students' digital skills have allowed e-textbooks to take root in different school subjects' pedagogical practices. E-educational resources played a particularly important role during the COVID-19 pandemic, as they greatly facilitated the reorientation of the learning process toward online schooling in many parts of the world, including Latvia: These resources allowed educators to teach students learning from different locations and ensured the continued quality of learning practices.

However, the development of and research into e-textbooks are still in their infancy. Principles for creating e-textbooks have not been sufficiently evaluated; as yet, more attention has been paid to educators'students' experiences and satisfaction with e-textbooks (e. g., McGowan et al., 2009; Sun \& Flores, 2012; Al-Qatawneh et al., 2019). Some research exists regarding critical analysis of e-textbooks' content, form, and interactivity; results indicate contradictory views on the effectiveness of e-textbooks (e. g., Choi et al., 2011; Gu et al., 2015; Gueudet et al., 2018; Pepin et al., 2016; Vītuma, 2019).

To understand e-textbooks, two definitions of textbooks are important. Jurman (1999) notes: "A textbook is part of methodologically didactic materials, cooperat[ing] with the teacher in the education process." In this sense, textbooks are largely intended for teachers who read, accept, and implement the methodological path proposed by the author(-s), and then for students in an educator-led learning process. Nose (2003) also remarks: "A textbook is a book that has been designed specifically for the needs of school education. It is a guide toward other sources of knowledge, toward discovering new knowledge." Thus, the successful e-textbook both meets the principles of a good learning material - by including purposeful content based on certain pedagogical theories and subject curriculum - and facilitates the creation of new methods for their practical use by encouraging innovative teaching approaches and techniques.

Another issue important to this article is the inclusion of meaningful illustrations in language e-textbooks - that is, illustrations that could be involved in the language learning process. Although it is relatively difficult to illustrate a language itself, the inclusion of images as learning resources in language textbooks is a well-established practice. Illustrations can show the use of language in different discourses. The study of such images' content, meanings, and pedagogical purposefulness is the focus of much research. Such images are often described in the context of the cultures of the target language (e. g., Yuen, 2011; Chapelle, 2016; Ziad \& Ouahmiche, 
2019). One issue that has not been addressed sufficiently in the analysis of language textbook images is the pedagogical role of images including texts from public or partly public spaces - linguistic landscape signs (hereinafter LL signs). Advertisements, direction signs, official announcements, instructions, and graffiti are a few examples of LL signs.

Chapelle (2020) and Burr (2021) have examined more than 50 textbooks of French and Latvian containing images with LL signs. Although the studies differ in their audience, the pedagogical goals of the sampled textbooks (respectively, students of French as a foreign language in the US; students of Latvian as a first, second, and foreign language mainly in Latvia), and in the research focus (respectively, Québec's cultural narratives; language awareness and sociolinguistic topics), the findings show similar features in the functioning of the images. Both scholars conclude that LL signs often have a passively illustrative function in language textbooks, without direct guidance to teachers/students on how to exploit them in the learning process. Textbooks most often do not include questions or tasks for engaging students in exploration and critical analysis of the images, nor do they encourage students to conduct empirical research of LL signs in students' known environments.

However, the last two years have seen the publication of two e-textbooks which use LL signs as their main starting point for teaching both language-teaching methodology and individual language and language-related topics. The first is A Guide for Exploring City Texts (Celvedis pilsētu tekstu izpētē in Latvian) (Berra (Burr), 2020), and the second is Linguistic Landscapes in English Language Teaching: A Pedagogical Guidebook (Solmaz \& Przymus, 2021).

The aim of this article is to compare these two e-textbooks in terms of their technological and pedagogical frameworks and to discuss the benefits, challenges, and disadvantages of using a language e-textbook which heavily utilizes LL signs.

With respect to e-textbooks, language teaching, and LL studies, this article provides an extensive survey of these e-textbooks. The sections of this article are as follows. First, a classification of e-textbooks; pedagogical directions of LL research; the Multiliteracies Framework; and principles of e-textbook content analysis are presented. Second, a comprehensive comparison of the e-textbooks is provided. Third, pedagogical benefits, challenges, and disadvantages are discussed. Finally, main conclusions are drawn and future research questions introduced. 


\section{Method}

Since the author of this article did not find other examples of e-textbooks with a focus on LL signs, the article discusses two e-textbooks as its research samples:

- Sample 1, A Guide for Exploring City Texts, 240 pages (Berra (Burr), 2020),

- Sample 2, Linguistic Landscapes in English Language Teaching: A Pedagogical Guidebook, 248 pages (Solmaz \& Przymus, 2021).

Preparatory work was done before a critical comparison of the e-textbooks. First, theoretical literature about the typology and technological aspects of e-textbooks was studied. Second, the research regarding LL pedagogy was reviewed. Third, the methodological framework used to guide the pedagogical work with both e-textbooks was explored. Finally, criteria for the content analysis of the textbooks were defined. Each of these steps is described in detail in the following subsections.

\section{Theoretical literature about e-textbook typology}

E-textbooks are mainly classified into three groups, according to their technical specifications and the variety of learning strategies they provide (e. g., Lee et al., 2012: 156; Lokar, 2015: 102; Dobler, 2015: 483; Gueudet et al., 2018: 541-542):

1. Traditional (also integrative, digitalized) e-textbooks are identical to printed textbooks and can be linked to other e-educational resources. Technical features are limited to highlighting, commenting, and using alongside other texts or online resources.

2. Enhanced (also evolving, living, or rich) e-textbooks with content through various media (e. g., video, podcasts, blogs, and print) and with social networking capabilities (e. g., sharing notes). The user can typically navigate to specific chapters or sections from the table of contents, zoom on images, and click on external hyperlinks.

3. Interactive e-textbooks combine features of traditional and enhanced textbooks and provide interactive content (e. g., 3D figures, interactive progress checks, games, and savable video responses).

Traditional and enhanced e-textbooks mainly are monolithic, consisting of a single large block in frequently used formats (txt, html, chm, pdf, epub). These e-textbooks are less designed for use in combination with other learning materials because their contents are not modular in construction. Educators cannot re-design them or edit the content, for instance, change the order of a relevant e-textbook's parts (e. g., a collection of exercises, texts, images, and project ideas), add, replace, or delete some parts (Lokar, 2015: 104-105; Gu et al., 2015: 28). 


\section{LL studies for teaching language}

LL research began at the end of the $20^{\text {th }}$ century. Over time, LL studies have become varied and complex (overview in Shohamy, 2019). A recurring theme in LL studies is the use of LL signs in language learning. So far, attention has centered on using the LL for contextual input in teaching a second language (e. g., Sayer, 2009; Gorter \& Cenoz, 2017; Malinowski, 2019; Malinowski et al., 2020). Researchers and instructors have often linked language learning to raising one's linguistic, cultural, and sociopolitical awareness of a target-language's speakers' environment. However, insufficient attention has been paid to the link between LL research and the creation of methodologies and textbooks. This gap is especially evident when it comes to first-language teaching.

\section{Methodological framework of the e-textbooks}

Authentic material is not only important in the development of an e-textbook which utilizes LL signs; the use of such materials also provides a pedagogical framework for teachers which allows (1) LL signs to be systematically integrated into the teaching process, (2) clear and logical continuity of texts and activities throughout the e-textbook, (3) further deepening of language knowledge and skills, and (4) further development of essential capabilities such as critical thinking, cooperation, civic responsibility, creativity, and multiliteracies.

Purposefully encouraging students to share their prior experiences and knowledge; empirically experience language/speech situations; research contexts; functionally and critically analyze texts; and create new ideas, texts, and knowledge are the successive pedagogical steps of the Multiliteracies Framework (Cope \& Kalantzis, 2015) and the Bridging Activities Framework (Thorne \& Reinhardt, 2008). These were applied in practice in the development of both e-textbooks. This methodology is detailed in both e-textbooks (Berra, 2020: 21-53; Solmaz \& Przymus, 2021: 10-36).

\section{Content analysis of the e-textbooks}

The qualitative approach to e-textbook research is based on seven criteria:

1. Type of e-textbook

2. Audience

3. Structure

4. LL signs and references to databases with LL signs

5. Other intertexts

6. Tasks and topics associated with LL signs

7. Languages. 


\section{Results}

Both e-textbooks are results of international projects. Sample 1 was one of the publications of the individual, three-year postdoctoral project "Linguistic Landscape of the City as a Multifaceted Resource in the Baltic States: Linguists', Entrepreneurs' and Students' Perspectives" (2017-2020). Sample 2 was the product of the intercontinental project "Linguistic Landscapes in English Language Teaching," or LLinELT (2019-2020).

Neither is called an e-textbook; Sample 1 is called "a popular-scientific edition in linguistics," while Sample 2 is called "an (interactive) e-book." Nevertheless, they refer to lessons or workshops for prospective teachers (students) and to learning in the language classroom, and thus can be considered e-textbooks. The word guide/guidebook in each's title functions as a reference to textbooks' recommendatory nature; both propose practical samples (tasks, activities, and lessons) for teacher education and language learning in the classroom.

The next subsections show the commonalities of and differences between the two e-textbooks.

\section{Type \& technical features of e-textbooks}

Both samples are enhanced e-textbooks (according to Lokar, 2015) as they allow the user to navigate to specific sections from the table of contents and contain hyperlinks to online resources.

Sample 1, unlike Sample 2, provides an option to zoom on images. In turn, Sample 2 has standalone sample-lessons containing high resolution images with/of LL signs in its third section.

Sample 2 includes clickable video screenshots in three of its sections, linking to short clips about theoretical concerns regarding and pedagogical ideas for the inclusion of LL signs into language-teaching practice; practicing educators, prospective teachers, and researchers are included in the clips.

Both e-textbooks are open-access educational materials. Both materials can be downloaded as a pdf file and used on an electronic device (laptop, tablet, or mobile phone).

\section{Audience}

The e-textbooks' main audience are both parties involved in education: educators and students. Similarly, researchers who are interested in language pedagogy, the study of public communication, language policies and ideologies, and multimodality will find these e-publications to be useful and will be inspired by other researchers' insights on interdisciplinary theories and practical experiences. 
Sample 1 is mainly useful material for Latvian as a first language (respectively L1) teachers (including prospective teachers) and methodologists to obtain (1) an overview of the latest linguistics theories and language-teaching approaches and techniques, (2) ideas for the implementation of Latvian national subject standard's sections "Language and Society" and "Media, Language, and Influence" in pedagogical practice.

Another target group is high school students, who may strengthen their knowledge of Latvian grammar, language functions in public communication, and language-use practices, improve their understanding of sociolinguistics development in Latvia, and develop research skills by compiling and critically analyzing language data. Although the e-textbook emphasizes the L1 perspective, study work is also possible in student groups with mixed levels of Latvian language skills; some parts of the e-textbook particularly are suitable for teaching Latvian to minority language students in Latvia.

Researchers will find this book useful for learning the LL research process and sample analyses of several multimodal signs.

Teachers of English as a second language (respectively L2) and foreign language, or EFL (including prospective teachers), are the main audience for Sample 2. However, "the materials and ideas put forward in this book can be adapted into different L2 teaching and learning settings" (Solmaz \& Przymus, 2021: 4). Several ideas tested by prospective teachers (book's contributors) are adaptable to teaching L1 at different ages (e. g., creating one's own classroom rules, acquiring cultural awareness through LL signs, and understanding the contextual uses of modal verbs).

This e-textbook, more than Sample 1, highlights the process of educating teachers both in national and international professional seminars and in face-to-face and online courses.

Young researchers in sociolinguistics and language pedagogy will particularly appreciate their peers' mini-research papers included in the book that relay prominent LL research themes and individual translanguaging practices caused by the expanded use of English around the world and its admixture with other foreign/local languages. The included papers also direct students to develop their scientific writing skills, for instance, showing them how to formulate objective and research questions, how to describe their methodology, and how to analyze data and summarize main findings.

\section{Structure}

Sample 1 contains seven parts: (1) Introduction, (2) Conceptual and Methodological Framework of the Edition for Educators, (3) Coverage of a Theoretical Framework or High School Students and Emerging Researchers, (4) City Texts Under a Research Magnifying Glass for High School Students, 
(5) Diving Deeper: Languages in Society and Sociolinguistics (chapter for high school students and emerging researchers), (6) Afterword, and (7) Recommended Literature.

The main body of the e-textbook consist of three parts: a theoretical and methodological part for educators, a theoretical and methodological part for students, and a practical part for students. Later, the fourth chapter is divided into four subchapters which are designed around LL signs: restriction and prohibition signs (19 pages in length); advertisements (46 pages); posters (35 pages), and graffiti (34 pages). The subchapters are structured considering the knowledge processes model of the Multiliteracies Framework (see in 2.3.). Each subchapter has five main parts:

1) a list of pedagogical benefits (or learning outputs, e. g., Learned information about design trends of posters in different periods and Selfcreated eye-catching poster) and keywords of the subchapter (or learning objectives, e. g., proper nouns, transliteration, uppercase letters, and abbreviations for Posters),

2) study work on the main concepts of the subchapter (respectively, first thoughts and definitions of LL signs and their associated terms, e. g., an advertisement, to advertise, commercials, misleading advertising, or advertisers),

3) a set of tasks designed around LL signs, arranged in four or five thematic subsections; each task has several questions that successively help students complete the task and address different perspectives (e. g., various social actors, different cases of language use, linguistic attitudes, several benefits of advertisements),

4) a summary and self-assessment tasks (open questions, tests, and/or rating scales), with questions for self-reflection,

5) references.

Sample 2 consists of eight sections featuring either theoretical or practical information about the introduction and implementation of LL-centered activities in English language classrooms: (1) About LLinELT Project, (2) The Pedagogical Model, (3) Literacies-Based Sample LL Lessons, (4) LL-Inclusive Practices, (5) Digital Symposium on Linguistic Landscapes: Keynote Talks and Panels, (6) Linguistic Landscape of My City: Mini Research Papers, (7) Sample Databases of Linguistic Landscapes, and (8) Bibliography.

The e-textbook combines methodological recommendations, language lesson plans, video of conference papers, and a compilation of databases valuable for pedagogical purposes (and brief descriptions of the databases).

Sample 2 contains 29 mini-samples of language lessons (each subsection is three pages long) based both on a content-based topic (e. g., Astronomy, Halloween, Modern Art Works, Multilingualism, and Black Lives Matter) 
and individual groups of LL signs by their placement (e. g., airport signs, subway signs, shop signs, T-shirt inscriptions, and COVID-19-related signs). Each of these subsections has a recommended language level and has a strong internal structure comprising six steps:

1) introduction (for teachers) to the topic and a short description of the lesson,

2) target vocabulary with simple definitions,

3) questions for students, to activate their experience and knowledge and discuss the topic,

4) questions for two or three image/text analyses,

5) digital resources for post-analysis practices, each indicating its mode (text, video, image),

6) three or four ideas for students' individual research, creative works, or group activities.

\section{LL signs and References to databases with LL signs}

LL signs from Latvian cityscapes, some indoor places (e. g., museums and libraries), newspapers, and the internet relevant to each subchapter are consistently included in Sample 1. Their number in one subchapter varies from 24 to 47 LL signs.

The theoretical and methodological chapters include other types of LL signs (e. g., store signs, direction signs, and plaques with business names) as well to show the diversity of LL signs and research topics and to discuss theoretical and methodological issues. The included LL signs represent Latvia's linguistic landscape (excepting two prohibition signs which are from the US).

The e-textbook irregularly provides references to the author's database of LL signs from the Baltic States and the author's blog, the national archive of photos with LL signs, a pictogram repository, road sign database, thematic homepages on social networks, forums, a digital poster repository, and printed publications useful for pedagogical purposes. As a supplementary material for students' independent work, a list of pictograms in various public places in other parts of the world (e. g., toilets, airports, and hotels) is given.

In case of Sample 2, the cover of the e-textbook already shows its focus; two photographs with written texts from public spaces give a hint to non-experts what linguistic landscape (LL) and LL signs mean. The e-textbook contains LL signs from different countries (mainly the US, but also Turkey, India, Australia, UK, and Canada), the outdoor and indoor LL, and the virtual LL. Examples include airport signs, tourism signs, shopping mall signs, restaurant signs, inscriptions on T-shirts, protest signboards, and graffiti. 
The location of the LL signs (via Google Maps) has been added to some of the photos.

Each sample lesson has two or three images with/of LL signs the choice of which is based on relevant thematic topic, not on LL sign type. Videos depicting LL-inclusive practices show authentic photos with/of LL signs, virtual walks exploring texts in different places (via Google Maps), and students' drawings with/of LL signs as a result of English learning activities in classroom.

This e-textbook provides a well-structured and clear overview of online resources that can be useful in the learning process. Such lists (e. g., open access repositories of movie posters, book covers, brand logos, menus, concert tickets, or graffiti) are given both in the description of each sample lesson and in a separate chapter of the e-textbook.

\section{Other intertexts}

Sample 1 demonstrates a great variety of texts related to each type of LL sign. Various texts by genre are included in the e-textbook: scientific and popular-scientific publications (conference theses, quotes and fragments from articles, covers and content of the latest sociolinguistics books), reference literature (city guide, entries from dictionaries and encyclopedias), legal texts (excerpts from laws and regulations), informative texts (news, posts, and instructions), literary texts (poems, fragments from fictions, dramas, and documentaries), folklore texts (sayings and folk songs), and critiques (reviews and comments on the internet).

Links to additional resources are also provided: for instance, e-educational materials (grammar reminders, language rules, and video lessons), online reference literature (recommendations and digital language tools), informative texts (statistics, video interviews, and movie descriptions), scientific and popular-scientific texts (videos of public talks and PowerPoint presentations), legal texts, and city websites. Mostly, the resources are explicitly labeled with prompting phrases such as If you want to know more about $X$, read/watch/listen.... Such phrases guide students' self-directed learning and unobtrusively offer different learning strategies.

In turn, Sample 2 includes separate, full-text papers in written and video format: theoretical contributions and practical studies on LL by researchers and teacher candidates. Sample lessons do not include other texts alongside LL signs, but they do incorporate links to some informative and literary texts, educational materials (e. g., TED Talks, articles, stories, movie trailers, lists, classroom activities, and worksheets). 


\section{Tasks associated with LL signs and languages topics covered}

Each practical subchapter of Sample 1 contains the following types of tasks:

1) warm-up tasks that introduce the topic and the specific type of LL sign (e. g., creating a mind map with associations, students sharing their experiences with specific LL sign types or communication situations),

2) tasks with terms, to comprehend the terms' meaning and use in different disciplines and languages (e. g., comparing the definitions of advertisement, writing ones' own definitions),

3) tasks on typical linguistic features of LL signs (e. g., imperatives on prohibition signs, metaphors in advertisements, clock time on posters, means of self-representation in graffiti),

4) tasks on language choice motivation and criteria,

5) tasks for the analysis of the use of several languages, comparing the functions of languages, the amount of information in all languages and its purposefulness,

6) tasks on semiotic resources used to express meanings in LL signs (e. g., analysis of women's role representation in advertisements),

7) tasks of extending the context of LL signs (e. g., socially relevant topics, interethnic tensions, and language ideology),

8) tasks on the relationship between the author and audience,

9) tasks for exploring the description, perception, and interpretation of LL signs in literary, informative, and entertaining texts,

10) tasks for clarification of the methodology and findings of LL analysis in popular-scientific and scientific texts,

11) creative tasks (e. g., creating posters, preparing tutorials, writing poems, and sketching),

12) project works (LL research in school, city, village, and on the internet),

13) self-assessment tasks.

Language topics of the e-textbook are related to linguistic terminology and methods - certain text genres and text types (e. g., public talk, dispute, review, essay), lexical groups and language styles (e. g., proper nouns, slang, figurative language, metaphors, and scientific language), typical grammatical forms, syntactic constructions, and principles of LL-sign text creation - and to issues regarding sociolinguistics and language policy (e. g., multilingualism, language prestige, language laws, and linguistic attitudes).

Mini lessons of Sample 2 include vocabulary lists, communicative tasks based on LL signs, and ideas for creative works and student research; the lessons exclude grammar tasks. Grammatical forms and syntactic 
constructions relevant to each communicative situation are implicitly practiced through conversations about images (e. g., the expression of time and place in describing an airport signboard image).

Questions about images with LL signs include not only reading texts in the target language (English), sharing associations and thoughts on LL signs' content and form, but also metalinguistic talks about various meaning-making resources (e. g., scripts, languages, colors, and pictograms) and their role and functionality in self-representation, communication, and social processes. Thus, language topics such as linguistic diversity, translanguaging, societal use of various English forms around the world, and English as a lingua franca are covered.

\section{Languages}

All texts included in Sample 1 are in their original languages (e. g., local languages - Latvian, Latgalian, Livonian, and Russian; foreign languages - English, German, and French). Many terms and their definitions are given in several languages; for instance, translations of the word ainava 'landscape' are provided in seventeen languages.

The main text of Sample 2 is in English, with authentic examples - LL signs and findings from LL studies - in other languages or undeterminable languages as well.

\section{Discussion}

This comparison of the two e-textbooks is ambitious in the sense that it perhaps would not be proper to compare L1 and L2 teaching materials. Each has its own purpose, its set of techniques and activities to be used, and its unique intended results. Nevertheless, the intention of this article is to show a variety of ways to work practically with LL signs, emphasizing that LL signs and the LL approach fit wonderfully into both L1 and L2 learning processes and that several ideas overlap or are adaptable from one language teaching practice to the other.

The comparison shows that e-textbooks' main technological advantage is hyperlinking, or instant movement from the e-textbook to an online resource and back, if there is an internet connection. Users will appreciate technical features such as bookmarking, highlighting, annotating, and searching.

The evaluation of the e-textbooks' content uncovers some pedagogical concepts they both share:

1) authenticity, which manifests itself in unmodified examples of language use (including LL signs), in the play and analysis of communicative situations, in the non-idealization of the language situation, 
in solving real-life problems, and in respecting students' identities, experiences, and opinions,

2) resourcefulness, which allows educators/students to choose from e-textbooks and recommended e-learning resources that which is needed for specific pedagogical goals and differentiation of the learning process according to ability and learning strategies,

3) connectivism, which applies to both micro- and macro- learning levels: the theoretical, methodological, and pedagogical parts of e-textbooks; e-textbooks and other thematically/genre-related resources; several e-textbook authors'/editors' works; various texts included in the e-textbooks; educators'/students' work on communication (public, semi-public, and private); places for students' pair/group work; co-operation between students and members of local communities; classroom and outdoor learning activities, and interdisciplinarity (e. g., combining several school subjects),

4) a focus on text genres, which on the one hand centers on various LL signs (included in the e-textbooks - photographed, found on the internet, or drawn by students), and on the other hand thematically, linguistically, and semiotically expands users' views on the LL signs, contextualizes and discursively challenges the signs.

The pedagogical beliefs and methodological preferences of e-textbook authors and editors can be seen through these concepts. Language is understood in the context of semiotic resources, so knowledge and skills in one language are inextricably linked to awareness and competences of other languages, semiotic consciousness, and multiliteracies. Texts as complex linguistic practices are analyzed in the contexts of communicative, cultural, socio-political, and ideological processes.

The learning process in both e-textbooks is designed in a way that students do not passively absorb knowledge, but interactively create and contribute knowledge and apply them in various real-life situations. This process is gradual and systematic based on the phase's/stage's principle. However, although both e-textbooks offer work with LL signs, each has its own starting points and goals. In Sample 1, each topic flows from a certain type of LL sign, while in Sample 2, the topic is what determines which type of LL signs fit in an individual learning activity or lesson. In other words, Sample 1 shows how to analyze language, meanings, and semiotic resources in LL signs, texts, and discourses related to LL signs, while Sample 2 shows how to include LL signs in different communicative topics for learning a language.

Understandably, learning L1 differs from learning a foreign language; therefore, the first approach allows one to talk about more complex texts, tasks, and discussion topics in the learning process. In Sample 1, the 
strategies, techniques, and means for creating LL signs and perceptions, analyses, and interpretations of LL signs by various social actors are extensively developed and scrupulously discussed with students. Interrelated texts meet the principles of deep reading. Similarly, sociolinguistics terms and topics are explored more deeply than in Sample 2.

An important difference between the e-textbooks is the language of the main body. Sample 1 is in Latvian; Sample 2 is in English. The latter thus has a broader range of potential readers and users. However, from a student perspective, multilingual practices and translanguaging are more promoted in the Sample 1.

There are a few disadvantages of the e-textbooks as well. The current technological features of the e-textbooks do not allow educators/students to change the order, length, or content of chapters, subchapters, or sections. Users should be aware that both e-textbooks can be downloaded to an electronic device, but registration for the Adobe Acrobat Pro paid service may be required to use all the tools and technical features of the $p d f$ file. There is always a risk that technical errors can occur, e. g., with websites that no longer exist.

From a student perspective, the lack of space for writing answers in e-textbooks can be frustrating. In the case of Sample 1, written tasks do not have space for answers (tables are exceptions), even if individual parts of the e-textbook are printed.

The amount of information on one page is crowded, which makes it burdensome to read on an electronic device. This applies to the theoretical parts of both e-textbooks and to the practical part of Sample 1.

Regarding the organization of teaching work, it must be acknowledged that none of the e-textbooks provides content for the entire individual study year/course, language level, or national subject standard in high school.

\section{Conclusions}

The compass metaphor in this article's title intends to demonstrate the function of a genre-focused e-textbook: as a tool to show one or more methodological way of conducting purposeful conversations with students about the diversity of semiotic resources, multimedia, and languages in today's world, to critically evaluate these diversities in various texts, and how to use all available resources responsibly. These metalinguistic conversations are especially important for the development of students' linguistic and multimodal awareness and the improvement of their multiliteracies.

E-learning resources have great potential to develop their habit of using digital language tools in everyday language practices, to critically evaluate 
information available online and to draw students' attention to valuable and high-quality open-access resources on the internet.

This comparison and discussion also have limitations, due to the small number of samples. The analysis of two e-textbooks (and two with different aims, at that) does not allow the results to be generalized. However, the article reveals some significant pedagogical benefits for the development of language e-textbooks with a focus on LL studies and LL signs. This revelation could be useful for planning and developing new e-educational resources which integrate various authentic texts, including LL signs.

Future research on language e-textbooks should examine the connectivity of different e-educational materials (both technologically and in their content) and their suitability for longer-term (semester- or year-long) courses. Practical research describing experiences using an e-textbook with a focus on LL signs would also be a useful contribution as regards the development of similar e-textbooks.

\section{References}

Al-Qatawneh, S., Alsalhi, N., Al Rawashdeh, A., Ismail, T. \& Aljarrah, K. (2019). To E-textbook or not to E-textbook? A quantitative analysis of the extent of the use of E-textbooks at Ajman University from students' perspectives. Education and Information Technologies, 24, 2997-3019.

Berra (Burr), S. (2020). Cel̦vedis pilsētu tekstu izpētēe. [A Guide for Exploring City Texts]. LU: Latviešu valodas institūts. https://dspace.lu.lv/dspace/handle/7/53310

Burr, S. (2021). Linguistic landscape signs in first language teaching materials: From passively illustrative function to meaningful learning experience. In E. Krompák, V., Fernández-Mallat \& S. Meyer (Eds.), Linguistic Landscapes and Educational Spaces. Multilingual Matters. In press.

Chapelle, C. A. (2016). Teaching culture in introductory foreign language textbooks. London: Palgrave Macmillan.

Chapelle, C. A. (2020) Linguistic landscape images and Québec's cultural narrative in French textbooks. In D. Malinowski, H. H. Maxim, \& S. Dubreil (Eds.), Language Teaching in the Linguistic Landscape Mobilizing Pedagogy in Public Space (pp. 43-67). New York, NY: Springer.

Choi, J., Heo, H., Lim, K., \& Jo, I. (2011). The development of an interactive digital textbook in middle school English. In T.-h. Kim et al. (Eds.), Future Generation Information Technology, 397-405. Berlin Heidelberg: Springer-Verlag

Cope, B. \& Kalantzis, M. (Eds.) (2015). A pedagogy of multiliteracies: Learning by design. New York: Palgrave Macmillan.

Dobler, E. (2015). E-Textbooks: A personalized learning experience or a digital distraction? Journal of Adolescent \& Adult Literacy, 58(6), 482-491.

Gorter, D. \& Cenoz, J. (2017). Linguistic landscape and multilingualism. In J. Cenoz, D. Gorter \& S. May (Eds.), Language Awareness and Multilingualism (pp. 233-245). Switzerland: Springer. 
Gu, X., Wu, B. \& Xu, X. (2015). Design, development, and learning in e-Textbooks: What we learned and where we are going. Journal of Computers in Education, 2(1), 25-41.

Gueudet, Ch., Pepin, B., Restrepo, A., Sabra H. \& Trouche, L. (2018). E-textbooks and connectivity: Proposing an analytical framework. International Journal of Science and Mathematics Education, 16, 539-558.

Jurman, B. (1999). Kako narediti dober učbenik na podlagi antropološke vzgoje, [How to develop a good textbook based on anthropological education]. Ljubljana: Jutro.

Lee, H. J., Messom, C., \& Yau, K. A. (2012). E-Textbooks: Types, characteristics and open issues. Journal of Computing, 4(9), 155-161.

Lokar, M. (2015). The future of E-Textbooks. International Journal for Technology in Mathematics Education, 22(3), 101-106.

Malinowski, D. (2019). Learning to translate the linguistic landscape. In M. Pütz \& N. Mundt (Eds.), Expanding the Linguistic Landscape: Linguistic Diversity, Multimodality and the Use of Space as a Semiotic Resource (pp. 58-71). UK/USA: Multilingual Matters.

Malinowski, D., Maxim, H. H. \& Dubreil, S. (Eds.) (2020). Language Teaching in the Linguistic Landscape Mobilizing Pedagogy in Public Space. New York, NY: Springer.

McGowan, M. K., Stephen, p. R., \& Bradley, C. W. (2009). Student perceptions of electronic textbooks. Issues in Information Systems, 10(2), 459-465.

Nose, Z. (2003). What is a textbook anyway? EDUCA, 12(3), 29-34.

Pepin, B., Gueudet, B., Yerushalmy, M., Trouche, L., \& Chazan, D. I. (2016). E-textbooks in/for teaching and learning mathematics: A potentially transformative educational technology. In L. English \& D. Kirshner (Eds.), Handbook of Research in Mathematics Education (pp. 636-661). New York: Taylor \& Francis.

Sayer, P. (2009) Using the linguistic landscape as a pedagogical resource. ELT Journal 64 (2), 143-154.

Shohamy, E. (2019). Linguistic landscape after a decade: An overview of themes, debates and future directions. In M. Pütz \& N. Mundt (Eds), Expanding the Linguistic Landscape: Linguistic Diversity, Multimodality and the Use of Space as a Semiotic Resource (pp. 25-37). UK/USA: Multilingual Matters.

Solmaz, O. \& Przymus, S. (Eds.) (2021). Linguistic Landscapes in English Language Teaching: A Pedagogical Guidebook. TCU Digital Repository. https://repository.tcu.edu/ handle/116099117/45344

Sun, J. \& Flores, J. (2012). E-Textbooks and Students' Learning Experiences. Journal of Innovative Education, 20(1), 63-78.

Thorne, S. \& Reinhardt, J. (2008). 'Bridging activities,' new media literacies and advanced foreign language proficiency. CALICO Journal, 25(3), 558-572.

Vītuma, M. (2019). E-grāmata - efektīvs mācību līdzeklis matemātikā. 4. un 5. klasei. [E-book - effective textbook of Math for grade 4 and 5]. Izglitiba un Kultüra, 2, 9.

Yuen, K. M. (2011). The representation of foreign cultures in English textbooks. ELT Journal, 65, 458-466.

Ziad, K., \& Ouahmiche, G. (2019). Gender positioning in the visual discourse of Algerian secondary education EFL textbooks: Critical image analysis vs teachers' perceptions. Journal of Language and Linguistic Studies, 15(3), 773-793. 